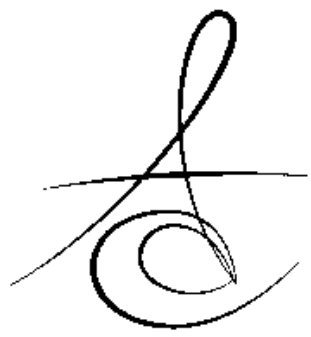

\title{
SABİT LİNGUAL RETAİNER YAPIMINDA KULLANILAN MATERYALLER VE UYGULAMA YÖNTEMLERİ
}

\section{WIRES THAT USED IN THE CONSTRUCTION OF FIXED LINGUAL RETAINERS AND APPLICATION METHODS}

\author{
Uzm. Öğr. Ayşe Ezgi BİÇER*
}

Doç. Dr. Hakan EL*

\author{
Makale Kodu/Article code: 2306 \\ Makale Gönderilme tarihi: 15.06 .2015 \\ Kabul Tarihi: 01.07.2015
}

öz

Aktif ortodontik tedavi ile hedeflenen amaçlara ulaşıldıktan sonra mevcut durumun korunması, önceki maloklüzyonun, diş hareketlerinin nüksetmesini önlemek için alınan önlemleri içeren ortodontik aşamaya 'retansiyon fazı' denmektedir. Retansiyonun sağlanması için sabit retainer kullanımı sıklıkla tercih edilen bir uygulama olup, literatürde bu amaç için kullanılan farklı boyutlarda, farklı materyallerde sabit retainer telleri ve farklı uygulama teknikleri mevcuttur. $\mathrm{Bu}$ derlemenin amacl; geçmişten günümüze sabit retainer yapımında kullanılan retainer telleri, sabit retainerların uygulama yöntemleri ile ilgili literatür çalışmalarını değerlendirmektir.

Anahtar Kelimeler: Lingual retainer, sabit retainer, retainer telleri

\section{GİRİŞ}

Aktif ortodontik tedavi ile hedeflenen amaçlara ulaşıldıktan sonra mevcut durumun korunması, önceki maloklüzyonun, diş hareketlerinin nüksetmesini önlemek için alınan önlemleri içeren ortodontik aşamaya 'retansiyon fazı' denmektedir ${ }^{1}$. Maloklüzyonların tedavisi ortodontik aygıtlar ile çeşitli mekanikler sağlanarak farklı süreçler dahilinde çözümlenebilmektedir. Ancak tedavi sonrasında retansiyon uygulanmaz ise veya başarılı bir pekiştirme süreci olmaz ise maloklüzyonun tekrar etmesi söz konusu olmaktadır ${ }^{1,2}$.

Tedavi sonrası malokluzyonun tekrar etme eğiliminde olmasının 3 önemli nedeni vardır.

1-Ortodontik diş hareketi sonrası gingival ve periodontal dokuların reorganizasyonu ve mevcut duruma adaptasyonu için belirli bir sürecin gerekli olmasl: Ortodontik diş hareketi histolojisine

\section{ABSTRACT}

Retention phase is protection of the current situation and prevention a recurrence of orthodontic tooth movement and previous maloclusion after active orthodontic treatment has been reached the intended objectives. Fixed retainers are often preferable for retantion in orthodontics. In the literature, wires in different sizes and materials are used in the construction of fixed retainers and different application techniques are available. The aim of the present review; evaluate the literature studies about wires that used in the construction of fixed retainers and application methods of fixed retainers until this time. Keywords: Lingual Retainer, fixed retainers, retainer wires

bakıldığında, aktif ortodontik tedavi ile kemikte remodeling olmaktadır. Apozisyon-rezorpsiyon olayları sonrasında yeni kemik oluşumu zaman gerektirmektedir. Ortodontik uygulamada diş hareketlerine bağlı olarak periodontal ve gingival liflerin düzeninde bozulmalar olmaktadır. Dişleri çevreleyen kollejen liflerin yapısında oluşan gerilimler ve yön değişikliklerinin tekrar duruma adaptasyonu için belirli bir zamana ihtiyaç vardır. Özellikle rotasyon hareketleri sonrası retansiyon çok daha önemli olmaktadır. Reitan ${ }^{3}$; rotasyon hareketinden sonra diş kökünün apeks, orta ve marjinal bölümünde bulunan gerilmiş periodontal liflerin, ne kadar süre sonra kendilerini yeniden düzenleyerek duruma uyum sağladıklarını araştırmıştır ve 232 günlük pekiştirme tedavisinden sonra, diş kökünün apeks ve orta bölgesindeki gerilmiş olan periodontal liflerde tam bir adaptasyon görülürken, marjinal periodontal liflerde kısmen adaptasyon gerçekleşmiştir. Bu nedenle,

* Hacettepe Üniversitesi Diş Hekimliği Fakültesi Ortodonti AD. 
rotasyon hareketlerinden sonra nüks oluşumunu engellemek için retansiyon tedavisine ek olarak marjinal periodontal liflerin kesilmesi önerilmiştir ${ }^{3}$. 2Değişen morfolojik yapı ve fonksiyon arasındaki uyumun tekrar sağlanmasr: Tedavi öncesinde uygun olmayan bir morfoloji varlığında dahi fonksiyonel bir denge söz konusudur. Diş kavisleri, alveol ve çene kemiklerini saran kasların ve yumuşak dokuların fonksiyonları arasında var olan dengenin tekrar sağlanabilmesi için belirli bir süreye intiyaç vardır ${ }^{4}$. 3-Büyüme gelişimin devam ettiği bireylerde değişen okluzal ve fonksiyonel denge: Ortodontik tedavi tamamlandığında eğer bireyin büyüme gelişimi devam ediyorsa, uygulanan iskeletsel, fonksiyonel veya dental tedavi sonrası, büyüme gelişim tamamlanana kadar retansiyon uygulaması önem arzetmektedir ${ }^{5}$. Zamanla gözlenen geç mandibular büyüme, dil-dudak basıncı arasındaki dengede değişiklikliğe neden olurken, fonksiyonel tedavi sonrası büyüme gelişim tamamlanmamış ise mevcut durumun tekrarlaması olası sıkıntılardandır. Çünkü büyümesini tamamlamamış bireylerde büyüme yönünde farklılık, kondiler adaptasyon ve yumuşak doku dengesi değişme eğilimindedir. Transvers boyut gelişimini erken dönemde tamamlandığı için bu yönde gözlenecek problemler oldukça nadirdir. Buna karşın anteroposterior ve vertikal yöndeki gelişim daha geç tamamlanmakta olup, retansiyon aşamasında klinik olarak daha sıkıntılı durumlara sebep olabilmektedir ${ }^{1}$.

\section{RETANSİYON SÜRESİ}

Arklardaki düzensizliklerin sabit ortodontik tedavi ile düzeltilmesi sonrası retansiyon tedavisi genel olarak ilk 5-6 ay apareyin tam zamanlı kullanımı, sonrasında 1 yıla kadar yarı zamanlı kullanımı şeklindedir. Büyüme gelişimi devam eden bireylerde ise büyüme tamamlanana kadar retansiyon apareylerinin yarı zamanlı kullanılması önemlidir.

\section{RETANSİYON}

\section{KULLANILAN APAREYLER}

1-Hareketli Retansiyon Apareyleri: En sık kullanılan ve tamamen pasif olan retansiyon apareyi 'Hawley' dir. En önemli avantajı ise posterior bölgede settlinge izin vermesidir. Bunun yanında keser stabilitesi için vakumla şekillenen retainerlar(essix), erişkin hastalarda estetik açıdan daha çok tercih edilmektedir.

2-Aktif Retainerlar: Retansiyon periodu boyunca, büyüme gelişime bağı veya bağlı olmadan minimal relapslar gözlenebilmektedir. Bu dönemde retainerlarla ufak diş hareketleri yapılabilmektedir. Bu amaçla kullanılan retainerlar 'aktif retainerlar' olarak adlandırılmaktadır.

3-Sabit Retainerlar: Ortodontik tedavilerin ardından maksiller ve mandibuler anterior bölgedeki boşlukların, çapraşıklıkların veya rotasyonların relapsını önlemek için uzun dönem retansiyona ihtiyaç vardır. Sabit ortodontik retainerlar bu amaç için sıklıkla tercih edilmektedir ${ }^{1,6,7}$. Sabit retainer kullanımı için 4 önemli endikasyon mevcuttur ${ }^{1}$; 1-Ortodontik tedavi sonrası, geç mandibular büyüme ile alt keserlerde oluşabilecek keser çapraşılığını önlemek için sıklıkla tercih edilmektedir. 16-20 yaş arası mandibular büyüme az miktarda olsa bile çapraşıklık oluşma eğiliminde olacaktır. Genelde bu durum büyümeye bağlı olarak kesici dişlerin daha lingualde konumlanmaya çalışması ile gerçekleşmektedir. 2-Diastema kapama tedavileri sonrası daimi olarak retasiyonun sağlanması gerekmektedir. Çünkü bu boşluklar tekrar açılma eğilimi göstermektedir. Bunun için hareketli retainerlar yetersiz kalmaktadır. 3-Tedavi sonrasında açılan köprü veya implant boşluklarının korunması amaçı olarak sabit retainerlara sıklıkla başvurulmaktadır. 4-Erişkin bireylerde diş çekimli tedavilerin ardından, kapatılan çekim boşluklarının retansiyonu aşamasında hareketli apareylerden daha iyi tolare edildiği için sabit retainerlar tercih edilmektedir.

\section{SABİT RETAINERLARIN GELİ̧̧İM SÜRECI}

Ortodontik ataçmanların diş yüzeyine direkt bondingi, ilk olarak 1965 yılında Newman ${ }^{8}$ tarafından rapor edilmiştir. Bu gelişme öncülüğünde retansiyon aşamasında sabit retainer uygulamaları başlamıştır. İlk bonded sabit retainer Kneirim ${ }^{9}$ tarafından 1973 yılında rapor edilmiştir. Dişler üzerine direkt bonding uygulamasının ön plana çıkması ile Kneirim; Kentucky Üniversitesi Ortodonti Bölümünde, bant uygulaması olmaksızın alt kanin-kanin arası retainer bondingini gerçekleştirmiştir. Bu yayın oldukça ilgi ve beğeni toplamış olup, aylarca bantlar üzerinden tedavi gören hastaların, retansiyon aşamasında da bantlı kanin dişlerle sürece devam etme konusundaki isteksizlerine de çözüm olmuştur. Çünkü maksillada Hawley retainerlar kullanılırken, mandibuler anterior bölge için sıklıkla kaninlere uygulanan bantlara lehimli lingual retainerlar kullanılmaktaydı. Bu ilk bonded retainer uygulamasında Knierim 0.028 inch yuvarlak paslanmaz çelik tel kullanmış olup, kaninlere gelen terminal uçlara 90 derecelik büküm vererek retansiyonu artırmayı hedeflemiştir. Kneirim'in ${ }^{9}$ rapor ettiği ilk bonded 
retainer tanıtımıyla birlikte ilk olarak düz, yuvarlak ortodontik teller bu amaç için kullanılmıştır. Lingual retainer kanin-kanin arası uygulanmış olup, sadece kanin dişlerden destek almıştır. Ardından, 1982 yıında ilk olarak Zachrisson ve Artun ${ }^{10}$ tarafından uygulanan ve yayınlanan çok sarımlı tellerle yapılan sabit retainerlar gündeme gelmiştir. 1983 de Zachrisson ${ }^{11}$ çok sarımlı 'dead wireları'anteriordaki 3-3 arası tüm dişlere uygulamış, bununla birlikte yıllardır çeşitli çaplarda ve özelliklerde flexible tellerle retansiyon sağlanmaya başlanmıştır. Genel anlamda yayınlara bakıldığında sıklıkla 0.0215 ve 0.0175 inch çok sarımlı teller bu amaç için kullanılmaktadır ${ }^{12,13}$. Günümüzde fiber destekli retainer materyalleri de, estetik olmaları nedeni ile kullanılmaktadır ${ }^{14,15}$. Geçmişten bugüne tedavi sonrası anterior dişlerdeki relapsı önlemede sabit lingual retainerların oldukça etkin olduğu yapılan çalışmalarda gözlenmiştir ve günümüzde sıklıkla tercih edilmektedir. En önemli avantajı ise hasta kooperasyonundan bağımsız olarak retansiyon sağlamasıdır ${ }^{11}$. Ortodontik tedavi sonrasında gerilen periodontal fiberlerin ve alveol kemiğin remodelingine dişleri destekleyerek izin veren bu retansiyon apareylerinin uygulanmasında kullanılan farklı materyaller mevcuttur ${ }^{16}$.

\section{SABITT RETAİNER YAPIMINDA KULLANILAN MATERYALLER}

Geçmişten güzümüze lingual retainer yapımında pek çok farklı materyal kullanıldığı örnekleri ile literatürde yer almaktadır ${ }^{9,16-21}$. Pek çok çalışma ${ }^{19-22}$ bu materyallerin başarı oranlarını birbirleri ile karşılaştırmış, ideal materyali bulmayı hedeflemiştir. Çoğunlukla uzun dönemlerde relaps önlemedeki etkinlikleri, periodontal problemlere sebebiyet verme intimalleri ve kırılma kopma gibi durumları değerlendirilmiştir ${ }^{19,20}$. Rotasyonlu premolarların düzeltimi sonrası labialden retainer uygulamaları ile periodontal remodelinge izin vermek bunlara örnek olarak verilebilmektedir ${ }^{22}$. Lingual retainerlar 2 temel dizaynda uygulanmaktadır ${ }^{18}$;

- Kanin-kanin arası rijid mandibular retainerlar

- Esnek tellerden yapılan sabit lingual retainerlar

\section{Retainerlar:}

1Kanin-Kanin Arası Rijid Mandibular

Rijid mandibular retainerlar bonding materyalindeki gelişimler ile uygulanan ilk retainerlardır. Rijid tellerin kullanımıyla sadece terminal dişler olan kanin dişlerden destek alan bu retainerların anterior dört keser üzerine bağlantısı bulunmamaktadır ${ }^{23}$. Sıklıkla bu amaç için 0.028 ya da 0.030 inch çelik teller kullanılmaktadır. Bu teller düz yuvarlak veya çok sarımlı olabilmektedir. Uygulama esnasında, kanin dişler üzerinde bağlantıyı artırmak amacı ile özel bükümler uygulanan bu retainerların, 20 yıllık takip sonrasında periodontal dokular üzerine olumsuz herhangi bir etkisi olmadığı gözlenmiştir ${ }^{23}$. Yapılan çalışmalarda kanin-kanin arası genişliği korumada oldukça başarılı bulunan bu retainerların aynı zamanda kesici rotasyonlarının relapsını önlemede etkin olmadığı gözlenmiş$\operatorname{tir}^{17,20-24}$. Sadece kanin dişler üzerine uygulanan bu retainerlar kesici dişlerin labilalizasyonuna da engel olamamaktadır ${ }^{25,26}$. Artun ve ark.'nın ${ }^{20}$ yapmış olduğu bir çalışmada, düz 0.032 inch çelik tel ve 0.032 inch çok sarımlı tel sadece kanin dişlerine uygulanırken, 0.0205 inch çok sarımlı tel tüm anterior dişlere uygulanmıştır. 3 yıl takip sonrası sadece kanin dişlere retainerın yapıştırıldığı grupta değişen derecelerde düzensizlik oluştuğu gözlenirken, tüm dişlere yapıştırılan retainer varlığında bu düzensizlik oranlarının anlamlı ölçüde azalma olduğu rapor edilmiştir. Sadece kanin dişlere yapıştırılan retainerların hazırlanması ve uygulamasının rahat olduğunu; anterior 6 dişe uygulanan retainerlara göre daha güvenilir ve hijyenik oldugunu savunan çalışmalarda mevcuttur 20,21,24. Çünkü sadece kanin dişlere yapıştırıldığı için temizlenmesi daha kolaydır. Kırılması sözkonusu olduğunda hasta tarafından daha kolay farkedilebilmektedir. Özellikle başlangıç aşa- masında anterior çapraşıklığı ve keser rotasyonları çok olmayan olgularda tercih edilmesi önerilmektedir ${ }^{21}$.

2-Esnek Tellerden Yapilan Sabit Lingual

\section{Retainerlar:}

Zachrisson ${ }^{21,22}$ tarafından çok sarımlı tellerin kullanılmaya başlanmasıyla, rijid kanin-kanin arası lingual retainerların yerini, anterior çapraşıklığı belirgin olan bireylerde daha esnek tellerle yapılan ve anteriorda tüm dişlere yapıştırılan sabit retainerlar almıştır 1,20,24. Günümüzde esnek tellerden yapılan bu sabit retainerlar altın standart olmakla birlikte, keser çapraşıklığının retansiyonunda oldukça etkin bulunmuş$\operatorname{lardır}^{1,27,28}$.

Esnek çok sarımlı tellerle yapılan sabit retainerların avantajları ${ }^{1,29}$ şu şekilde sıralanabilir; -Düzensiz yüzeye sahip olması nedeni ile, diş üzerine bonding uygulamasında retansiyonun artması; -Kolay uyumlanabilir ve uygulanabilir olması; -Rahat temizlenebilir olması $^{30}$; -Hareketli retainerlarla birlikte kullanımının mümkün olması; -Okluzal temaslardan uzağa yerleştirilebilmesi mümkün olması; -Fizyolojik diş hareketle- 
rine izin vermesidir. Dezavantajları ${ }^{29}$ ise; -Hastanın oral hijyen motivasyonunun zorunlu olmasl; -Bonding esnasında aşıı yapıstııı kullanımına bağlı dişeti çekilmesi riski olmasl; -Telde meydana gelebilecek deformasyon veya pasif olmayan uygulamalar sonrası istenmeyen diş hareketi oluşturabilmesi; -Derin örtülü kapanış olgularında kullanımının kısıtlı olmasıdır.

Renkema ve ark. ${ }^{31} ; 221$ hastaya uyguladıkları, flexible sarımlı 0.0195 inch tellerle yapılan ve tüm diş yüzeyine uygulanan lingual retainerların debonding sonrası 5. yılda, 200 hastada \%90.5 oranında başalı sonuçlar gösterdiğini rapor etmişlerdir. Ancak, retainer yapımı sonrası düzenli hekim kontrolünün olması gereliliği çoğu yazar tarafından vurgulanmıştır. Literatürde, bu retainerlarda oluşan kopma veya deformasyona bağlı istenmeyen diş hareketlerini olduğunu gösteren vaka raporları da dikkat çekmektedir ${ }^{32,33}$. Dietrich ve arkadaşlarını ${ }^{34}$, 2015 de yayınlana makalelerinde; $0.016 \times 0.016$ inch lik çelik telden hazırladıkları ve tüm maksiller kesicilere uyguladıkları retainerların 5 yıllık takibi sonrasında, bu retainerların periodontal sağık üzerine herhangi bir olumsuz etkisinin bulunmadığını ve maksiller sabit retainerların uzun dönem stabilitesi ve koruyuculuklarından söz etmenin mümkün olduğunu belirtmişlerdir. Literatür tarandığı zaman, tüm kesici dişler üzerine bondingi gerçekleştirilen sabit retainerlar için çok farklı materyal seçimi olduğu görülmektedir. Bunlara bakacak olursak; -0.0175 inch, 0.0195 inch twist ${ }^{1} ;-0.0175,0.0195,0.0215$ inch 3 ve 5 sarımlı paslanmaz çelik tel ${ }^{16} ;-0.0195,0.0215$ inch çok sarımlı deadwire ${ }^{35} ;-0.018,0.022$ mil çok sarımlı paslanmaz çelik tel $1984^{36} ;-0.015$ inch çok sarımlı paslanmaz çelik ${ }^{37}$; Retrangular $0.016 \times 0.016,0.016$ x0.022 inch) çok sarımlı paslanmaz çelik ${ }^{38} ;-0.021$ inch çok sarıml. ${ }^{39} ;-0.0195,0.0215$ inch çok sarımlı paslanmaz çelik ${ }^{13} ;-0.017 \times 0.028$ inch çok sarımlı ${ }^{40}$; 0.0215 inch çok sarımlı ${ }^{17} ;-0.0175$ inch çok sarımlı ${ }^{41}$; $0.016 \times 0.022$ inch 8 sarımlı dead soft wire çelik tel ${ }^{21}$; 0.0215 inch 5 sarımll, $0.016 \times 0.022$ inch 8 sarımlı dead soft wire; 0.0195 inch dead soft ${ }^{42} ;-0.0195$ inch heat treated 3 sarımlı twist flex, 0.0215 inch 6 sarımlı çelik tel ${ }^{28} ;-0.016 \times 0.016$ inch paslanmaz çelik tel ${ }^{3}$.

Zachrisson $^{21}$, özellikle maksiller sabit lingual retainer uygularken, dental modeller üzerinde detaylı değerlendirme yapmayı önermiştir. Eğer bu değerlendirme yapılmaz ise okluzal kontaktların oluşabileceğini belirtmiştir. Yapmış olduğu bir çalışmada ise maksillar lingual retainerda başarısızlık oranlarının mandibular retainerlara göre yaklaşık 2 kat daha fazla olduğunu rapor etmiştir ${ }^{21}$. -Dahl ve Zachrisson'un ${ }^{43}$ 1991 yılında yaptığı çalışmada; 0.0195 ve 0.021 inch lik 3 sarımlı tellerle oluşturulan ve 29 hastaya uygulanan lingual retainerların ortalama $5.7 \mathrm{yll}, 5$ sarımlı 0.0215 inch lik tellerden oluşturulan ve 17 hastaya uygulanan lingual retainerların 3.2 yıl takibi sonrası relaps oluşmadığı; -Artun ve ark larının ${ }^{20} 1997$ yılında yaptıkları çalışmada; 11 hastaya uyguladıkları düz telden yapılış, kalın çok sarımlı tellerden yapılmış kanin kanin arası uygulanan lingual retainerların 3 yıl takibi sonrası anlamlı oranda relaps oluştuğu; -Andren ve ark $^{44}$ larının 1998 yılında yaptıkları çalışmalarında; çok sarımlı değişik çaplarda çok sarımlı tel kullanarak oluşturdukları lingual retainerların uygulandığı 52 hastanın ortalama 6.8 yıl takibi sonrası $\% 23$ oranında hafif relaps oluştuğu; -Störmann ve Ehmer'in ${ }^{26} 2002$ yllında yaptıkları çalışmada 0.0195 inch çapındaki çok sarımlı telden yapılan lingual retainerların uygulandığı 31 hastanın 2 yıl takibi sonrası relaps görülmediği; 0.0215 inch çapındaki telden yapılan retainerların uygulandığı 39 hastanın 2 yıl takibi sonrası \%20 oranında hafif relaps görüldüğü; düz kalın telden yapılan 3-3 arası retainer yapılan 34 hastanın 2 yıl takibi sonrası ise \% 80 oranında relaps oluştuğu rapor edilmiştir. Çok sarımlı ve düz çelik teller dışında estetik özellikleri nedeni ile kullanımı tercih edilen fiber destekli retainerlar (Resim 1) da mevcuttur. Polietilen destekli şeritler, 0.024 inch ça- pında fiber destekli 'Everstick Ortho' retainer desteleri bunlara örnek olarak verilebilmektedir. İlk jenerasyon fiber retainerlar çok rijid olması nedeni ile fizyolojik diş hareketini kısıtlamıştır. Zamanla önceden polimelilme- takrilata emdirilen fiber destekli 'EverStick Ortho' şeritlerin ortaya çıkması ve bonding materyallerindeki gelişmelere bağlı olarak pek çok sıkıntının üstesinden gelinmiştir ${ }^{15}$. Özellikle metal alerjisi olan bireylerde tercih edilebilen bu materyalin model üzerine uyumlanmasına gerek yoktur. Direkt hasta ağzında kolaylıkla uyumlanabilmektedir.

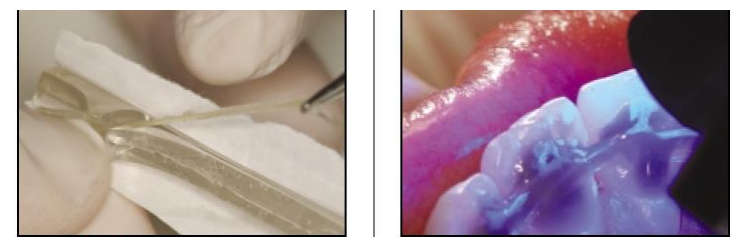

Resim 1. Fiber destekli retainer (Everstick Ortho) 


\section{SABİT LİNGUAL RETAİNER UYGULAMA YÖNTEMLERI}

Son 20 yıl içerisinde sabit retainerların uygulanması ile ilgili direkt ve indirekt olmak üzere iki yöntem geliştirilmiştir ${ }^{45}$. Günümüzde de her iki yöntem kabul görmekte ve tercih edilmektedir.

1-Direkt uygulama yöntemi: Dişler üzerine klinikte direkt uygulamanın yapıldığı bu yöntemde, retainer telinin planlanan dişler için önceden hazırlanması gerekmektedir. Bunun için önceden alınan dental modeller üzerinde veya hasta ağzında deneyerek uyumlama yapılabilmektedir. Literatürde kabul gören uygulama ${ }^{45-47}$; debonding öncesinde retainer yapilacak çeneden ölçü alınarak dental modellerin elde edilmesi ve model üzerine istenen materyaller ile retainerların hazırlanmasıdır. Dişlerin lingualinde maksimum teması pasif şekilde sağlamaya, her iki çene için de yapılacak ise mutlaka oklüzyonda temasların olmamasına ve debonding sonrası aynı randevuda retainerın yapıştııımasına dikkat edilmelidir. Retainerlar hazırlanırken mutlaka dişetinin dolduramadığı embrasurler dikkate alınmalıdır. Mevcut aralıklarda retainerlar modifiye edilerek; dişetine doğru büküm yapılarak singulumunun hemen üzerine uyumlanması ideal olacaktır. Büküm işlemi model üzerinde gerçekleştirilen retainerlar hasta ağzına uyumlanırken dişler üzerinde pasif olarak sabit kalabilmesi için kullanılan farklı yöntemler mevcuttur. Bunlar ${ }^{45-53}$ (Resim 2); parmak yardımı ile sabit tutmak, dental floss, elastik ligatürler, ligatür telleri ile sabitlemek, ortodontik mumların kullanımı, springlerin kullanımı ile sabitleme, ortodontik elastik zincir, ortodontik separatörler ile sabitleme, magnetler kullanılarak sabitleme, ağız içine taşıyıcı ajanlar(heavy body...) dır.

İnterproksimal alanlardan dental floss, elastikler, ligatür teli gibi materyaller önceden bükülmüş olan retainerın stabilitesini sağlarken, dişler üzerine kolaylıkla bondingi gerçekleştirilebilecektir. Bunun dişında özellikle ortodontik mumlar terminal dişler üzerinde tellerin sabitliğini sağlayabilmekte, hekimin zamandan tasarruf ederek uygulamayı tamamlamasına yardımcı olabilmektedir. Parmak basıncı uygulamasının tercih edilmesine bağı tel üzerinde deformasyonlar oluşabilmektedir ve sonuçta retainer başarıSı ile pasifliği olumsuz yönde etkilenmektedir. Bu uygulamalar esnasında retainerın doğru yere yerleştirilememesi, asit uygulanan yüzeyin kontaminasyon riski, stabilizasyona yardımcı uygulamaların retainerın uygun olmayan konumda yerleşmesine öncülük etmesi gibi problemler nedeni ile indirekt yöntem geliştirilmiştir.

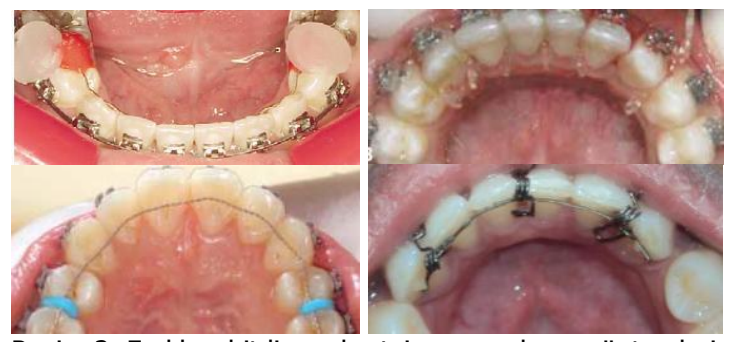

Resim 2. Farklı sabit lingual retainer uygulama yöntemleri

2-İndirekt uygulama yöntemi ${ }^{39,51,52,54}$ : En önemli özelliği laboratuvar ortamında bahsedilen sıkıntılar oluşmadan alçı modeller üzerine lingual retainerın istenen seviyede hazırlanıp bondinginin yapılması olan bu yöntem (Resim 3); klinik uygulama zamanının kısaltılması açısından tercih edilebilmektedir. Direkt uygulamaya göre en önemli avantajı retainerların istenen pozisyonda sabitlenebilmesidir. Aynı zamanda diş yüzeylerinin kontaminasyonunu da önlenmektedir. Bu avantajlara karşın bazı dezavantajları da yok değildir. Oldukça hassas olan bu yöntem de laboratuvarda geçirilen sürenin fazla olması ve klinikte uygulama sonrası bonding ajanının gingival embraşurlere taşması yöntemin sıkıntılarından olup, bu durum periodontal sağlığı olumsuz yönde etkileyebilmektedir.

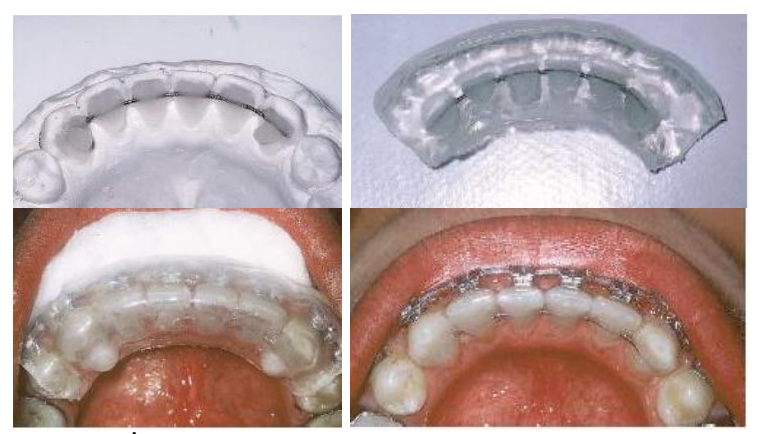

Resim 3. İndirekt sabit lingual retainer uygulama yöntemi

\section{SONUÇ}

Genel olarak bakıldığında en çok tercih edilen ve başarı açısından en iyi bulunan materyaller çok sarımlı tellerdir. Fizyolojik diş hareketine izin vermesi, bonding materyaline tutuculuğunun iyi olması ve ralapsı önlemede etkin olması sebebi ile çok sarımlı teller sıkıkla kullanılmaktadır. Uygulama açısından pek çok yöntem tanıtılmış olmasına ramen, hekim ve hasta açısından en uygun yöntemin tercih edilmesi önemlidir.

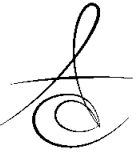


Retainerın kapsadığı dişler, dişlerin lingualinde uygulanacağı seviye tedavi sonunda model üzerinde yapılacak detaylı değerlendirme ile belirlenmelidir. Sonrasında uygulama açısından tercih edilecek yöntem hekimin tercihi ile ilgili olup klinik pratik ön plana çıkmaktadır. Düzgün diş temasları olan, pasif olarak dişler üzerine uygulanan ve sonrasında iyi bir izolasyonla başarılı şekilde bondingi yapılan retainerlar başarı oranı en yüksek olacak olan retainerlardır.

\section{KAYNAKLAR}

1. William R.Proffit, Henry W.Fields, David M.Sarver. Contemporary orthodontics. 5 ed. Mosby, Elsevier: 2013.

2. Ülgen M. Ortodontik Tedavi Prensipleri. 7. Baskı. Ankara Üniversitesi Basımevi: 2010.

3. Reitan RA. A review of the retantion problem: Angle Orthod 1960; 30: 179-194.

4. McNamara JAJr. Neuromuscular and skeletal adaptations to altered orofacial function: Am J Orthot 1973; 64: 578-606.

5. Nanda RS, Nanda SK. Considerations of dentofacial growth in long-term retantion and stability: Is active retantion needed? Am J Orthod Dentofac Orthhop 1992; 101: 297-302.

6. Bearn DR. Bonded orthodontic retainers: a review. Am J Orthod Dentofacial Orthop 1995; 108: 20713.

7. Lang G, Alfter G, Goz G, Lang GH. Retention and stability-taking various treatment parameters into account: J Orofac Orthop 2002; 63: 26-41.

8. Newman GV. Epoxy adhesives for orthodontic attachments: Progress report: Am J Orthod 1965; 51: 901-12.

9. Kneirim RW. Invisible lower cuspid to cuspid retainer: Angle Orthod 1973; 43: 218-9.

10. Artun J, Zachrisson BU. Improving the handling properties of composite resin for direct bonding: Am J Orthod 1982; 81: 269-76.

11. Zachrisson BU. The bonded lingual retainer and multiple spacing of anterior teeth: Journal of Clinical Orthodontics 1983; 17: 838-44

12 .Chen RS. Prefabricated bonded mandibular retainer: J Clinl Orthod 1978; 12: 788-9.

13. Weisser J. Bonded twin lower 3-3 retaining arch: J Clin Orthod 1978; 12: 557-60.

14. Diamond M. Resin fiberglass bonded retainer: J Clin Orthod 1987; 21: 182-3.

15. Geserick M, Ball J, Wichelhaus A. Bonding fiberreinforced lingual retainers with color-reactivating flowable composite: J Clin Orthod 2004; 38: 560-2.

16. Taner T, Aksu M. A prospective clinical evaluation of mandibular lingual retainer survival: Eur J Orthod 2012; 34: 470-474.

17. Butler J, Dowling P. Orthodontic bonded retainers: Journal of the Irish Dental Association 2005; 51: 29-32.

18. Hegde N, Reddy YG, Vinay P, Handa A. Bonded retainers in orthodontics: $A$ review. İnternational J Dent Clin 2011; 3: 53-54.

19. Scribante A, Sfondrini FM. Broggini S. Efficacy of esthetic retainers: Clinical comparison between multistranded wires and direct-bond glass fiberreinforced composite splints: Hindawi Publishing Corporation International J Of Dentistiy 2011; 1155: 548356-61.

20. Artun J, Spadafora TA, Shapiro AP. A 3-year follow-up study of various types of orthodontic canine-to canine retainers: Eur J Orthod 1997; 19: 501-509

21. Zachrrisson Björn U. Long term Experience with Direct-bond Retainers: Update and Clinical Advice: Journal of Clinical Orthodontics 2007; 41: 728-37.

22. Axelsson S. and Zachrisson BU. Clinical experience with direct-bonded labial retainers: J Clin Orthod 1992; 26: 480-90.

23. Booth FA, Edelman JM, Proffit WR. Twenty-yearfollow-up of patients with permanently bonded mandibular canine to canine retainers: Am J Orthod Dentofac Orthop 2008; 133: 70-76.

24. Renkema AM, Al-Assad S, Bronkhorst E, Weindel S. Effectiveness of lingual retainers bonded to the canines in preventing mandibular incisor relapse. Am J Orthod Dentofac Orthop 2008; 134: 179-80.

25. Zachrisson B. Third-generation mandibular bonded lingual 3-3 retainer: J Clin Orthod 1995; 29: 39-48.

26. Störmann I, Ehmer U. A prospective randomized study of different retainer types: J Orofacial Orthop 2002; 63: 42-50

27. Watted $N$, Wieber M,Teuscher T, Schmitz N. Comparison of incisor mobility after insertion of canine-to-canine lingual retainers bonded to two or to six teeth: A clinical study. J Orofac Orthop 2001; 62: 387-96.

28. Sifakakis I, Pandis N, Eliades T, Makou M. In-vitro asessment of the forces generated by lingual fixed retainers: Am J Orthod Dentofacial Orthop 2011; 139: 44-8. 
29. Parshan KM, Jain KRA. Review on flexible spiral wire retainer. J Dent Med Sci 2014; 13: 24-6.

30. Baydaş B, Kavrut F. Ortodontik tedavi gören bireylerde farklı gargaraların ağız sağlığına etkilerinin değerlendirilmesi: Atatürk Üniv Diş Hek Fak Derg 2005; 15: 12-21.

31. Renkema AM, Renkema A, Bronkhorst E, Katsaros C. Long-term effectiveness of canine-to-canine bonded flexible spiral wire lingual retainers: Am J Orthod Dentofacial Orthop 2011; 139: 614-21.

32. Pazera P, Fudalej P, Katsaros C. Severe complication of a bonded mandibular lingual retainer: Am J Orthod Dentofac Orthop 2012; 142: 406-9.

33. Katsaros C, Livas C, Renkema AM. Unexpected complications of bonded mandibular lingual retainers: Am J Orthod Dentofac Orthop 2007; 132: 838-41

34. Dietrich $P$, Patcas R, Pandis N, Eliades T. Long term follow-up of maxillary fixed retention: survival rate and periodontal health. European J of Orthodontics 2015; 37: 37-42.

35. Artun J. Caries and periodontal relation associated long term use of different types of bonded lingual retainers: Am J Orthod 1984; 86; 112-8.

36. Becker A, Goultschin J. The multistrand retainer and splint: Am J Orthod 1984; 85: 470-4.

37. Sheridan JJ. Incremental removal of bonded lingual retainers: J Clin Orthod 1988; 22: 116-117.

38. Southard KA, Southard TE. Conservative management of anterior spacing and deep bite: $A$ case report. Quintessence Int 1990; 21: 807-11

39. Corti FA. An İndirect-Bonded Lingual Retainer. Journal of Clinical Orthodontics 1991; 25: 631-2.

40. Willmot DR, Davies SJ. The use of light cured resin and orthodontic archwire to immobilise a transplanted maxillary canine: $\mathrm{Br}$ Dent J 1991; 170: 267-8.

41. Hobson RS, Eastaugh DP. Silicone putty splint for rapid placement of direct-bonded retainers: J Clin Orthod 1993; 27: 536-7.

42. Baysal A, Uysal T, Gül N, Ramoglu SI. Comparison of three different orthodontic wires for bonded lingual retainer fabrication: Korean J Orthod 2012; 42: $39-46$.

43. Dahl EH, Zachrisson BU. Long-term experience with direct-bonded lingual retainers: J Clin Orthod. 1991;25:619-630.
44. Andre'n A, Asplund J, Azarmidohkt E, Svensson R, Varde $\mathrm{P}$, Mohlin B. A clinical evaluation of long term retention with bonded retainers made from multi-strand wires: Swed Dent J 1998; 22: 123-31

45. Vibhute PJ. Two new methods for direct bonding 'lingual retainers': J Indian Soc Pedod Prevent Dent 2009; 27: 111-5.

46. Lee JS, Ihm JA, Ahn SJ. Time-saving fixed lingual retainer using Duralay resin transfer: American Journal of Orthodontics and Dentofacial Orthopedics 2004; 125: 203-5.

47. Karaman Aİ, Polat Ö, Büyükyılmaz T. A practical method of fabricating a lingual retainer: Am J Orthod Dentofac Orthop 2003; 124: 327-30.

48. Karthikeyan MK, Ramachandraprabhakar, Saravanan R, Rajvikram N, Kuppuchamy. Stabilising Springs for Fixed Lingual Retainer: J Clin Diagnostic Res 2013; 7: 2647-8.

49. Al-Emran S, Barakati RA. Method for Stabilizing a Lingual Fixed Retainer in Place Prior to Bonding: The Journal of Contemporary Dental Practice 2007; 8: 108-13:

50. Hattarki SR, Keluskar KM. Sequring a Lingual Retainer Wire with Orthodontic Separators: J Clin Orthod 2012; 46: 41.

51. Sahu SK, Jayam BK, Barik AK. Retainer Positioner: The journal of Indian Orthodontic Society 2012;46: 53-4.

52. Yadav S, Upadhyay M. Easy to Bond Lower Lingual Retainer: J Clin Orthod 2006; 40: 502.

53. Hahn W, Fricke J, Zech SE, Zanf A. The use of a neodymium-iron-boron magnet device for positioning a multi-stranded retainer in lingual retention -a piloy study in humans: Eur J Orthod 2008; 30: 433-6.

54. Rossouw PE, Joseph VP. Indirect Fabrication of a Bonded Lower Lingual Retainer: J Clin Orthod 1992; 26: 413-15.
Yazışma Adresi
Uzm. Öğr. Ayşe Ezgi BİÇER
Hacettepe Üniversitesi
Diş Hekimliği Fakültesi
Ortodonti Anabilim Dalı
Kat:7 Sıhhiye/ANKARA
TIf: 03123052290
e-mail: a.ezgibicer@gmail.com 